\title{
Emergence of Letermovir-resistant HCMV UL56 mutant during rescue treatment in a liver transplant recipient with ganciclovir-resistant infection HCMV: a case report
}

Stefania Paolucci ${ }^{1 \dagger}$, Giulia Campanini ${ }^{1 \dagger}$, Irene Cassaniti ${ }^{1}$, Alessandra Tebaldi ${ }^{2}$, Federica Novazzi ${ }^{1}$, Alice Fratini ${ }^{1}$, Antonella Meini ${ }^{3}$, Federica Girelli ${ }^{3}$, Laura Palumbo ${ }^{3}$, Alessandro Plebani ${ }^{3}$ and Fausto Baldanti ${ }^{1,4^{*}}$

\begin{abstract}
Background: Human Cytomegalovirus (HCMV) still represents a crucial concern in solid organ transplant recipients (SOTRs) and the use of antiviral therapy are limited by side effects and the selection of viral mutations conferring antiviral drug resistance.

Case presentation: Here we reported the case of an HCMV seronegative patient with common variable immunodeficiency (CVID), multiple hepatic adenomatosis, hepatopulmonary syndrome and portal hypertension who received a liver transplant from an HCMV seropositive donor. The patient was treated with Valganciclovir (VGCV) and then IV Ganciclovir (GCV) at 5 week post-transplant for uncontrolled HCMV DNAemia. However, since mutation A594V in UL97 gene conferring resistance to ganciclovir was reported, GCV therapy was interrupted. Due to the high toxicity of Foscarnet (FOS) and Cidofovir (CDV), Letermovir (LMV) monotherapy at the dosage of $480 \mathrm{mg}$ per day was administered, with a gradual viral load reduction. However, a relapse of HCMV DNAemia revealed the presence of mutation C325Y in HCMV UL56 gene conferring resistance to LMV.

Conclusions: In conclusion, even if LMV is an effective and favorable safety molecule it might have a lower genetic barrier to resistance. A warning on the use of LMV monotherapy as rescue treatments for HCMV GCV-resistant infections in transplant recipients is warranted.
\end{abstract}

Keywords: Case report, HCMV, Letermovir

\section{Background}

Antiviral drugs for treatment of systemic human cytomegalovirus (HCMV) infection in immunocompromised patients include viral DNA synthesis inhibitors Ganciclovir (GCV)/Valganciclovir (vGCV), Foscarnet (FOS) and Cidofovir (CDV). However, these drugs are

*Correspondence: fausto.baldanti@unipv.it; f.baldanti@smatteo.pv.it †'Stefania Paolucci and Giulia Campanini contributed equally to this work

${ }^{1}$ Molecular Virology Unit, Microbiology and Virology Department,

Fondazione IRCCS Policlinico San Matteo, Pavia, Italy

Full list of author information is available at the end of the article limited by significant side effects and the selection of viral mutations conferring antiviral drug resistance [1]. While GCV-resistant HCMV infections represent a crucial issue in transplant setting, being associated with higher risk of recurrent HCMV disease and high mortality rate [2, 3], FOS and CDV are used as rescue drugs for the treatment of GCV-resistant HCMV infections, because of their renal toxicity. Recently, new drugs with innovative mechanisms of action have been introduced in clinical practice, including Letermovir (LMV) which block the HCMV viral terminase 
complex and thus inhibits the cleavage/packaging of viral genomes [4, 5]. To date, due to very favorable safety profile, LMV has been approved for prophylaxis in hematopoietic stem cell transplant recipients (HSCTRs) [6]. On the other hand, some studies suggest that LMV might have a lower genetic barrier to resistance [7, 8]. Here, we report the rapid emergence of a LMV-resistant HCMV mutant in a liver transplant recipient undergoing LMV rescue treatment because of GCV-resistant HCMV infection, severe myelosuppression and kidney function impairment. This report is a warning on the use of LMV in monotherapy.

\section{Case presentation}

A 23-year-old woman with common variable immunodeficiency (CVID) was affected by multiple hepatic adenomatosis complicated by hepatopulmonary syndrome and portal hypertension. Renal dysfunction, fungal skin infections, sinusitis, otomastoiditis, and hypothyroidism were also documented. Immunoglobulins substitution therapy and replacement therapy for hypothyroidism were also administered. In October 24 2018, she received an orthotropic liver transplant. At the transplantation baseline, the patient was HCMV seronegative while her donor was HCMV-seropositive. Immunosuppressive therapy included steroids $(5 \mathrm{mg} /$ day) and tacrolimus (0.5 mg/day) (Fig. 1). HCMV

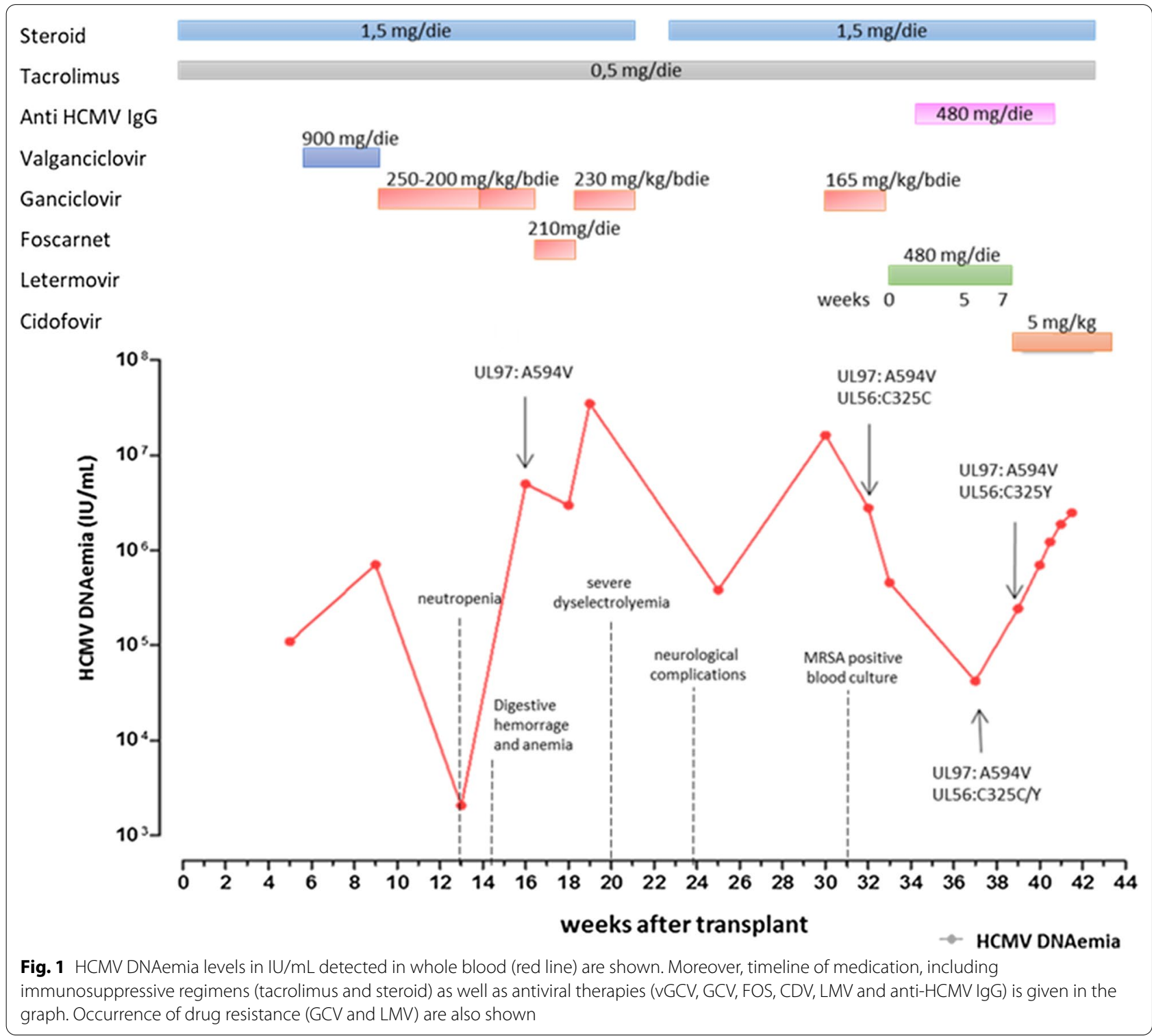


DNAemia of $111,000 \mathrm{UI} / \mathrm{mL}$ was reported 5 weeks post-transplant. VGCV treatment (900 mg twice daily) was introduced. After 11 weeks of vGCV treatment viral load continued to increase up to $713,567 \mathrm{UI} / \mathrm{mL}$, thus intravenous (IV) GCV treatment at $250 \mathrm{mg}$ twice daily was introduced two weeks later, IV GCV dosage was reduced at $200 \mathrm{mg}$ twice daily to minimize myelotoxicity. However, HCMV DNAemia after 13 weeks of treatment was still positive (2076 IU/mL). Colonoscopy and endoscopy performed in order to exclude HCMVrelated enteritis did not show relevant finding. At that time, therapy was interrupted due to the worsening of neutropenia.

At week 14, the patient was hospitalized for digestive hemorrhage and anemia. Then, she was transferred at Stroke Unit for limb hyposthenia due to concomitant cerebral ischemic event.

At week 16, HCMV DNAemia increased up to 3,000,000 UI/mL and mutation A594V in UL97 gene conferring resistance to GCV and vGCV was documented [9]. UL54 gene analysis excluded FOS resistance [10], thus FOS treatment $(90 \mathrm{mg} / \mathrm{kg}$ three times daily) was initiated. Unfortunately, due to the onset of severe dyselectrolyemia, FOS was discontinued after 10 days of treatment and a rapid increased of HCMV DNAemia $(35,000,000 \mathrm{IU} / \mathrm{mL})$ was observed. GCV was initiated at the dosage of $230 \mathrm{mg}$ twice daily but it was suspended after two weeks due to the very limited effect on HCMV DNAemia and worsening of anemia and thrombocytopenia.

At week 20, since the patient was highly immunosuppressed, tacrolimus was reduced and steroid was suspended. However, steroid had to be reintroduced after one week due to the onset of neurological complications. At that time, HCMV specific T-cell response determined by ELISpot assay [11] was undetectable, since the patient showed $91 \mathrm{CD} 4 \mathrm{~T}$ cells/ $\mu \mathrm{l}$, and $71 \mathrm{CD} 8 \mathrm{~T}$ cells/ $\mu \mathrm{l}$.

At week 21 the patient was hospitalized due to a respiratory distress, caused by HCMV lung infection and a methicillin-resistant Staphylococcus aureus (MRSA) septicemia.

GCV therapy was reintroduced in combination with HCMV-specific immunoglobulin therapy $(400 \mathrm{mg} /$ $\mathrm{kg}$ once a week for two weeks and after 14 and 21 days reduced at $200 \mathrm{mg} / \mathrm{kg}$ ). In addition, linezolid and daptomicin were administered for MRSA positive blood culture. A594V in UL97 gene was re-confirmed in blood sample. At week 30, HCMV viral load increased to $16,314,793 \mathrm{IU} / \mathrm{mL}$.

At week 32 post-transplant, oral LMV treatment was started in monotherapy at a dose of $480 \mathrm{mg}$ daily because of persisting neutropenia and a previous renal toxicity during FOS treatment. HCMV-specific T-cell response was still undetectable at that time when in presence of 76 CD4 and $67 \mathrm{CD} 8$ absolute T cells counts/ $\mu \mathrm{l}$.

At LMV baseline, HCMV DNAemia was 2,800,980 $\mathrm{IU} / \mathrm{mL}$. After two weeks of therapy, HCMV DNAemia decreased to $461,160 \mathrm{IU} / \mathrm{mL}$. Five weeks after starting LMV HCMV DNAemia was 42,336 IU/mL. Unfortunately, after 7 and 8 weeks of treatment HCMV DNA increased to $244,566 \mathrm{IU} / \mathrm{mL}$ and 703,080 IU/mL, respectively (Fig. 1). Thus, HCMV UL51, UL56 and UL89 genes encoding the terminase complex verify the potential emergence of LMV-resistance-associated mutation [12]. Mutation C325Y in HCMV UL56 terminase gene conferring high-level resistance to LMV $[8,13]$ was reported. Retrospectively, it was revealed that the mutation was already present as mixture with the wild type after 5 weeks LMV treatment. The patient was treated with $\mathrm{CDV}$ at the dosage of $5 \mathrm{mg} / \mathrm{kg}$ once a week. After 1-week CDV treatment, HCMV DNA increased up to 2,563,208 $\mathrm{IU} / \mathrm{mL}$. Emergence of CDV resistance was excluded by UL54 gene sequence analysis. The patient died after two weeks due to complications caused by HCMV infection.

\section{Discussion and conclusions}

HCMV infection and the associated tissue diseases are still important causes of morbidity and mortality in immunocompromised-transplanted patients, especially in subjects at high risk such as HCMV-seronegative recipients who receive an organ from an HCMV-seropositive donor $(\mathrm{D}+/ \mathrm{R}-)$, due to the lack of prior HCMV immune response [14]. Limited treatment options are available when side effects like nephrotoxicity, electrolyte disturbances, and myelotoxicity or drug resistance occur. Recent studies indicated that LMV might be an important addition to the current strategies in HCMV disease as salvage therapies in SOTRs $[15,16]$. LMV appears to be a good alternative to other antiviral especially in view of the favorable safety [17]. However, mutations conferring resistance to LMV have been reported both in HSCT and in SOT recipients [17-20] as soon as after 6 weeks of treatment [18]. Similarly, Hofmann and colleagues reported $\mathrm{C} 351 \mathrm{Y}$ mutation in two patients treated with LMV after emergence of GCV-resistance. In both cases, a mismatch $\mathrm{D} / \mathrm{R}$ was reported [21].

In the case here described, an even faster breakthrough of resistant HCMV during third-line treatment with LMV is reported. In this patient, congenital immunodeficiency associated with iatrogenic immunosuppression, primary HCMV infection likely concurred to the emergence of the GCV-resistance viral strain. Furthermore, LMV could only be administered in monotherapy due to significant myelo- and renal toxicity. It might be suggested that administration of LMV in higher dosage could be more effective, however in a 
recent study selection of LMV resistance was reported in two patients treated with $720 \mathrm{mg}$ and $960 \mathrm{mg}$ respectively [22]. Therefore, the use of LMV alone might be not sufficient to impair high level of HCMV replication $[17,18,21]$. Moreover, according to international consensus guidelines, monitoring of cell-mediated response should be included in management of solid organ transplant recipients [14].

In conclusion, a warning on the use of LMV monotherapy as rescue treatment for HCMV GCV-resistant infections in transplant recipients is warranted; thus combination therapy, if the patient's condition permits, may provide better results in case of high viral load.

\section{Abbreviations}

GCV: Ganciclovir; vGCV: Valganciclovir; FOS: Foscarnet; LMV: Letermovir; HCMV: Human cytomegalovirus; CVID: Common variable immunodeficiency.

\section{Acknowledgements}

We thank Daniela Sartori for careful preparation of the manuscript.

\section{Author's contributions}

SP: data analysis and interpretation, drafted the article; GC: concept and design of the work; IC: samples collection and data analysis; FN, AF: samples collection and experimental design; AM, FG, LP, AP and AT: clinical data collection and patient enrollment; FB: critical revision of the article and final approval of the version. All authors contributed toward data analysis, drafting and revising the paper, gave final approval of the version to be published and agree to be accountable for all aspects of the work. All authors read and approved the final manuscript.

\section{Funding}

This work was supported by the Fondazione IRCCS Policlinico San Matteo, Ricerca Corrente (grant 80207) and Ministero della Salute, Ricerca Finalizzata (RF-2019-12370797). The funders had no role in study design, data collection and analysis, decision to publish, or preparation of the manuscript.

\section{Availability of data and materials}

All data generated or analysed during this study are included in this published article.

\section{Declarations}

\section{Ethics approval and consent to participate}

This study was performed according to guidelines of the Institutional Review Board of the Fondazione IRCCS Policlinico San Matteo on the use of biologic specimens for scientific purpose in keeping with Italian law (art.13 D. Lgs. 196/2003).

\section{Consent for publication}

Patient next-of-kin gave written consent for relative's clinical details to be published in this study.

\section{Competing interests}

The authors report no conflicts of interest in this work.

\section{Author details}

${ }^{1}$ Molecular Virology Unit, Microbiology and Virology Department, Fondazione IRCCS Policlinico San Matteo, Pavia, Italy. ${ }^{2}$ Unit of Infectious Diseases, ASST Papa Giovanni XXIII, 24129 Bergamo, Italy. ${ }^{3}$ Pediatrics Clinic, Department of Clinical and Experimental Sciences, University of Brescia, ASST Spedali Civili of Brescia, Brescia, Italy. ${ }^{4}$ Department of Clinical, Surgical, Diagnostic and Pediatric Sciences, University of Pavia, Pavia, Italy.
Received: 3 December 2020 Accepted: 14 September 2021

Published online: 23 September 2021

\section{References}

1. Lurain NS, Chou S. Antiviral drug resistance of human cytomegalovirus. Clin Microbiol Rev. 2010;23(4):689-712.

2. Avery RK, Arav-Boger R, Marr KA, Kraus E, Shoham S, Lees L, Trollinger B, Shah P, Ambinder R, Neofytos D, Ostrander D, Forman M, Valsamakis A. Outcomes in transplant recipients treated with foscarnet for ganciclovirresistant or refractory cytomegalovirus infection. Transplantation. 2016;100(10):e74-80. https://doi.org/10.1097/TP.0000000000001418.

3. Minces LR, Nguyen MH, Mitsani D, Shields RK, Kwak EJ, Silveira FP, Abdel-Massih R, Pilewski JM, Crespo MM, Bermudez C, Bhama JK, Toyoda Y, Clancy CJ. Ganciclovir-resistant cytomegalovirus infections among lung transplant recipients are associated with poor outcomes despite treatment with foscarnet-containing regimens. Antimicrob Agents Chemother. 2014;58(1):128-35.

4. Goldner T, Hewlett G, Ettischer N, Ruebsamen-Schaeff H, Zimmermann H, Lischka P. The novel anticytomegalovirus compound AIC246 (Letermovir) inhibits human cytomegalovirus replication through a specific antiviral mechanism that involves the viral terminase. J Virol. 2011;85(20):10884-93.

5. Frange P, Leruez-Ville M. Maribavir, brincidofovir and letermovir: Efficacy and safety of new antiviral drugs for treating cytomegalovirus infections. Med Mal Infect. 2018;48(8):495-502.

6. Marty FM, Ljungman P, Chemaly RF, Maertens J, Dadwal SS, Duarte RF, Haider S, Ullmann AJ, Katayama Y, Brown J, Mullane KM, Boeckh M, Blumberg EA, Einsele H, Snydman DR, Kanda Y, DiNubile MJ, Teal VL, Wan H, Murata Y, Kartsonis NA, Leavitt RY, Badshah C. Letermovir prophylaxis for cytomegalovirus in hematopoietic-cell transplantation. N Engl J Med. 2017;377(25):2433-44.

7. Razonable RR. Role of letermovir for prevention of cytomegalovirus infection after allogeneic haematopoietic stem cell transplantation. Curr Opin Infect Dis. 2018;31(4):286-91.

8. Chou S. Rapid in vitro evolution of human cytomegalovirus UL56 mutations that confer letermovir resistance. Antimicrob Agents Chemother. 2015;9(10):6588-93.

9. Lurain NS, Weinberg A, Crumpacker CS, Chou S. Sequencing of cytomegalovirus UL97 gene for genotypic antiviral resistance testing. Adult AIDS Clinical Trials Group-CMV Laboratories. Antimicrob Agents Chemother. 2001;45(10):2775-80.

10. Baldanti F, Lilleri D, Campanini G, Comolli G, Ridolfo AL, Rusconi S, Gerna G. Human cytomegalovirus double resistance in a donor-positive/recipient-negative lung transplant patient with an impaired CD4-mediated specific immune response. J Antimicrob Chemother. 2004;53(3):536-9.

11. Calarota SA, Chiesa A, Scaramuzzi L, Adzasehoun KMG, Comolli G, Mangione F, Esposito P, Baldanti F. Normalizing ELISPOT responses to T-cell counts: a novel approach for quantification of HCMV-specific CD4(+) and CD8(+) T-cell responses in kidney transplant recipients. J Clin Virol. 2014;61(1):65-73.

12. Pilorgé L, Burrel S, Ait-Arkoub Z, Agut H, Boutolleau D. Human cytomegalovirus (CMV) susceptibility to currently approved antiviral drugs does not impact on CMV terminase complex polymorphism. Antiviral Res. 2014;11:8-12. https://doi.org/10.1016/j.antiviral.2014.08.014.

13. Goldner T, Hempel C, Ruebsamen-Schaeff H, Zimmermann H, Lischka P. Geno- and phenotypic characterization of human cytomegalovirus mutants selected in vitro after letermovir (AIC246) exposure. Antimicrob Agents Chemother. 2014;58(1):610-3.

14. Kotton CN, Kumar D, Caliendo AM, Huprikar S, Chou S, Danziger-Isakov L, Humar A, The Transplantation Society International CMV Consensus Group. The third international consensus guidelines on the management of cytomegalovirus in solid-organ transplantation. Transplantation. 2018;102(6):900-31.

15. Lischka P, Zimmermann $\mathrm{H}$. Antiviral strategies to combat cytomegalovirus infections in transplant recipients. Curr Opin Pharmacol. 2008;8(5):541-8.

16. Chemaly RF, Ullmann AJ, Stoelben S, Richard MP, Bornhäuser M, Groth C, Einsele H, Silverman M, Mullane KM, Brown J, Nowak H, Kölling K, Stobernack HP, Lischka P, Zimmermann H, Rübsamen-Schaeff H, Champlin RE, Ehninger G. AlC246 Study Team Letermovir for cytomegalovirus 
prophylaxis in hematopoietic-cell transplantation. N Engl J Med. 2014;370(19):1781-9.

17. Frietsch JJ, Michel D, Stamminger T, Hunstig F, Birndt S, Schnetzke U, Scholl S, Hochhaus A, Hilgendorf I. In vivo emergence of UL56 C325Y cytomegalovirus resistance to letermovir in a patient with acute myeloid leukemia after hematopoietic cell transplantation. Mediterr J Hematol Infect Dis. 2019;11(1):e2019001. https://doi.org/10.4084/MJHID.2019.001.

18. Jung S, Michel M, Stamminger T, Michel D. Fast breakthrough of resistant cytomegalovirus during secondary letermovir prophylaxis in a hematopoietic stem cell transplant recipient. BMC Infect Dis. 2019;19(1):388. https://doi.org/10.1186/s12879-019-4016-1.

19. Knoll BM, Seiter K, Phillips A, Soave R. Breakthrough cytomegalovirus pneumonia in hematopoietic stem cell transplant recipient on letermovir prophylaxis. Bone Marrow Transplant. 2019;54(6):911-2.

20. Cherrier L, Nasar A, Goodlet KJ, Nailor MD, Tokman S, Chou S. Emergence of letermovir resistance in a lung transplant recipient with ganciclovir-resistant cytomegalovirus infection. Am J Transplant. 2018;18(12):3060-4.

21. Hofmann E, Sidler D, Dahdal S, Bittel P, Suter-Riniker F, Manuel O, Walti $L N$, Hirzel C. Emergence of letermovir resistance in solid organ transplant recipients with ganciclovir resistant cytomegalovirus infection: a case series and review of the literature. Transpl Infect Dis. 2021;23(3):e13515.

22. Turner N, Strand A, Grewal DS, Cox G, Arif S, Baker AW, Maziarz EK, Saullo $\mathrm{JH}$, Wolfe CR. Use of Letermovir as salvage therapy for drug-resistant cytomegalovirus retinitis. Antimicrob Agents Chemother. 2019:63(3):e0233718. https://doi.org/10.1128/AAC.02337-18.

\section{Publisher's Note}

Springer Nature remains neutral with regard to jurisdictional claims in published maps and institutional affiliations.
Ready to submit your research? Choose BMC and benefit from:

- fast, convenient online submission

- thorough peer review by experienced researchers in your field

- rapid publication on acceptance

- support for research data, including large and complex data types

- gold Open Access which fosters wider collaboration and increased citations

- maximum visibility for your research: over $100 \mathrm{M}$ website views per year

At BMC, research is always in progress.

Learn more biomedcentral.com/submissions 